\title{
Whole-genome sequencing in an autism multiplex family
}

Lingling Shi ${ }^{1 \dagger}$, Xu Zhang ${ }^{2,3 \dagger}$, Ryan Golhar ${ }^{4}$, Frederick G Otieno ${ }^{4}$, Mingze $\mathrm{He}^{3}$, Cuiping Hou ${ }^{4}$, Cecilia Kim , Brendan Keating ${ }^{4}$, Gholson J Lyon ${ }^{4,5}$, Kai Wang ${ }^{1,4^{*}}$ and Hakon Hakonarson ${ }^{4,6^{*}}$

\begin{abstract}
Background: Autism spectrum disorders (ASDs) represent a group of childhood neurodevelopmental disorders that affect 1 in 88 children in the US. Previous exome sequencing studies on family trios have implicated a role for rare, de-novo mutations in the pathogenesis of autism.
\end{abstract}

Methods: To examine the utility of whole-genome sequencing to identify inherited disease candidate variants and genes, we sequenced two probands from a large pedigree, including two parents and eight children. We evaluated multiple analytical strategies to identify a prioritized list of candidate genes.

Results: By assuming a recessive model of inheritance, we identified seven candidate genes shared by the two probands. We also evaluated a different analytical strategy that does not require the assumption of disease model, and identified a list of 59 candidate variants that may increase susceptibility to autism. Manual examination of this list identified ANK3 as the most likely candidate gene. Finally, we identified 33 prioritized non-coding variants such as those near SMG6 and COQ5, based on evolutionary constraint and experimental evidence from ENCODE.

Although we were unable to confirm rigorously whether any of these genes indeed contribute to the disease, our analysis provides a prioritized shortlist for further validation studies.

Conclusions: Our study represents one of the first whole-genome sequencing studies in autism leveraging a large family-based pedigree. These results provide for a discussion on the relative merits of finding de-novo mutations in sporadic cases versus finding inherited mutations in large pedigrees, in the context of neuropsychiatric and neurodevelopmental diseases.

\section{Background}

Autism spectrum disorders (ASDs) are childhood neurodevelopmental disorders characterized by impairments in social interaction, communication, and by restricted, repetitive, and stereotyped patterns of behavior [1]. The Centers for Disease Control and Prevention (CDC) reported in 2012 that approximately 1 per 88 children in the United States has a diagnosis of ASD [2]. Boys are five times more likely to have ASDs than girls. Although autism is typically thought of as a childhood disorder, some affected patients need care even after they reach adulthood. In fact, a recent study

\footnotetext{
* Correspondence: kaiwang@usc.edu; hakonarson@email.chop.edu ${ }^{\dagger}$ Equal contributors

'Department of Psychiatry, Zilkha Neurogenetic Institute, Keck School of Medicine, University of Southern California, Los Angeles, CA 90089, USA ${ }^{4}$ Center for Applied Genomics, Children's Hospital of Philadelphia, Philadelphia, PA 19104, USA

Full list of author information is available at the end of the article
}

demonstrated that it can cost about $\$ 3.2$ million to take care of an autistic individual over his or her lifetime [3]; therefore, autism presents a great social and economic toll on society.

Understanding the causes of ASDs is critical for the development of better diagnoses and treatment strategies. ASDs are highly heritable and are indeed among the most heritable neurodevelopmental and neuropsychiatric disorders [4]. The genetic basis of ASDs has been pursued aggressively over the past few decades using cytogenetic studies, linkage analysis, and candidate gene association analysis [5]. With the development of high-throughput SNP genotyping technologies, genomewide association studies (GWAS) [5-9] and copy number variation (CNV) studies [10-13] have been conducted over the past few years, revealing the association between specific candidate genes and loci with ASDs, but with moderate effect sizes.

\section{() Biomed Central}


Recent genetic studies demonstrated that nextgeneration sequencing (NGS) technology can be a powerful tool to identify the genetic basis of human diseases, especially Mendelian disorders [14-16]. Unlike GWAS that relies on proxy association of genetic variants with unknown disease causal variants, NGS technology enables researchers to interrogate the complete human genome or exome for the detection of both common and rare variants, hence improving the chance of finding disease causal variants, given the potential ability to perform functional annotation on each of the identified variants. Recently, several studies have been published to examine the role of whole-exome sequencing (WES) to identify genetic risk factors for autism. In 2011, a trio-based study of autism performed WES on 60 individuals from families affected with sporadic ASDs and 20 unaffected control individuals, and suggested that de-novo sequence variants might contribute to the genetic etiology of ASDs [17]. A follow-up study from the same group sequenced 209 families and found that de-novo mutations fall within a highly interconnected $\beta$-catenin/chromatin remodeling protein network [18]. A companion paper using WES on 928 individuals, including 200 phenotypically discordant sibling pairs, reported that highly disruptive (nonsense and splice-site) de-novo mutations in brain-expressed genes are associated with ASDs and carry large effects [19]. Another study sequenced 175 trios by WES and nominated CHD 8 and KATNAL2 as genuine autism risk factors, but also suggested a more limited role for the contribution of de-novo mutations to ASD pathogenesis than previously reported [20]. Similarly, an exome sequencing study on 343 families did not identify significantly greater numbers of de-novo missense mutations in affected versus unaffected children, but they identified more genedisrupting mutations in affected children and found that many of the disrupted genes are associated with the fragile $\mathrm{X}$ protein FMRP [21]. The rate of de-novo mutations has been recently linked to paternal age, in a study that sequenced 78 trios including 44 offspring with autism and 21 offspring with schizophrenia [22]. Another study sequenced balanced chromosomal translocations in patients with autism or related neurodevelopmental disorders, and revealed the disruption of 33 loci from four categories, reinforcing a polygenic risk model of autism [23]. These and many other recently published studies suggested that de-novo mutations may play important roles in susceptibility to autism.

However, current exome sequencing studies on autism may not be comprehensive or representative enough. Many of these studies focus only on simplex families or sequence one affected child from multiplex families. More importantly, the published studies do not specifically analyze inherited mutations, despite the fact that
ASDs are highly heritable and that the vast majority of the mutations identified are inherited mutations. We note that one rare exception was published recently, which demonstrated that some familial ASDs were associated with biallelic mutations in known Mendelian disease genes [24]. Although it is clear that de-novo mutations explain a fraction of autism patients, it is likely that inherited mutations, in combination or in aggregation, may explain a higher fraction of autism cases. Therefore, we attempted to address this problem by performing a pilot sequencing analysis on patients from multiplex families. We selected a large two-generation family, with parents and eight children, two of whom were diagnosed with autism. DNA samples were available for all subjects, except for one unaffected child. We generated whole-genome sequencing data on the two probands. Not knowing the exact disease model for autism in the family, we performed a series of different procedures for removing variants that are less likely to be functionally important and for finding candidate disease causal genes. Additionally, we genotyped all members of the pedigree (except for the one unaffected child) using Illumina HumanHap550 SNP arrays with approximately 550,000 SNP markers, to help further reduce the number of candidate genes. We have not yet proven whether these mutations singly or in combination contribute to the development of this disease in the two children in this family, and we discuss the potential implications of our study, as a more general issue to the use of NGS for the study of autism and other neuropsychiatric disorders.

\section{Methods}

\section{Sample selection and sequencing}

We manually reviewed all large pedigrees at the Autism Genetic Resource Exchange (AGRE) [25] with >8 subjects, and selected a family for next-generation sequencing. The pedigree includes two parents and eight children, two of whom were affected with autism (Figure 1). The DNA samples for all members of the pedigree were retrieved from the AGRE, and all of them were de-identified subjects. The study was approved by Institutional Review Board of the Children's Hospital of Philadelphia. After quality control to ensure lack of genomic degradation, we sent 10 ug DNA of two probands to Complete Genomics (CG) in Mountain View, CA, USA for sequencing.

The whole-genome DNA was sequenced with a nanoarray-based short-read sequencing-by-ligation technology [26], including an adaptation of the pairwise endsequencing strategy [27]. Reads were mapped to the National Center for Biotechnology Information (NCBI) reference genome build 36 . The short reads alignment and variant calling were performed by the CG pipeline 


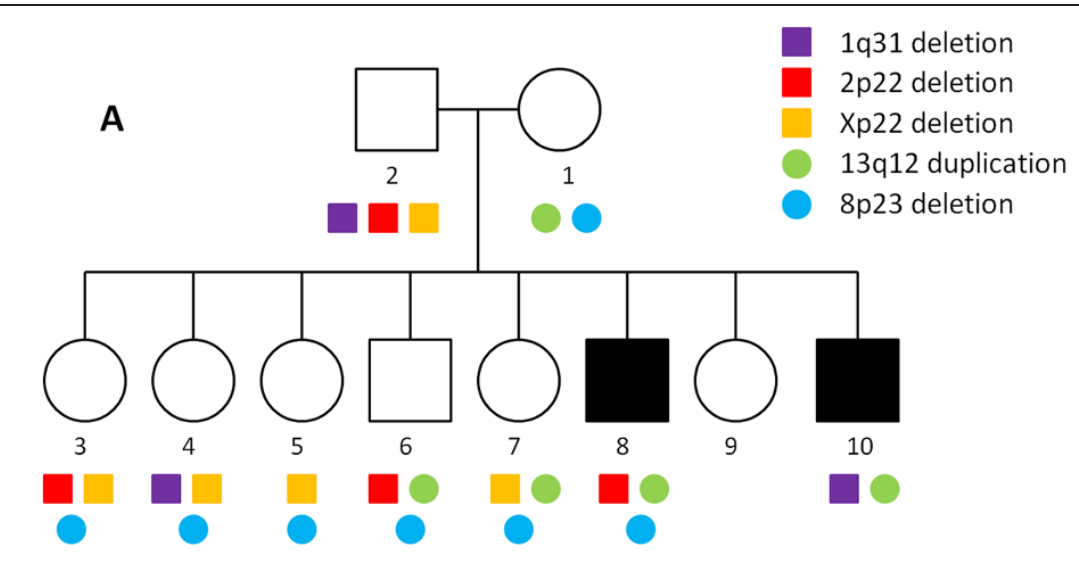

B

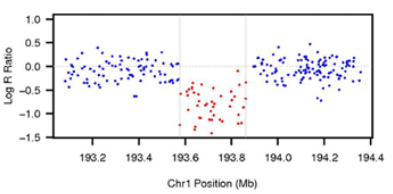

C
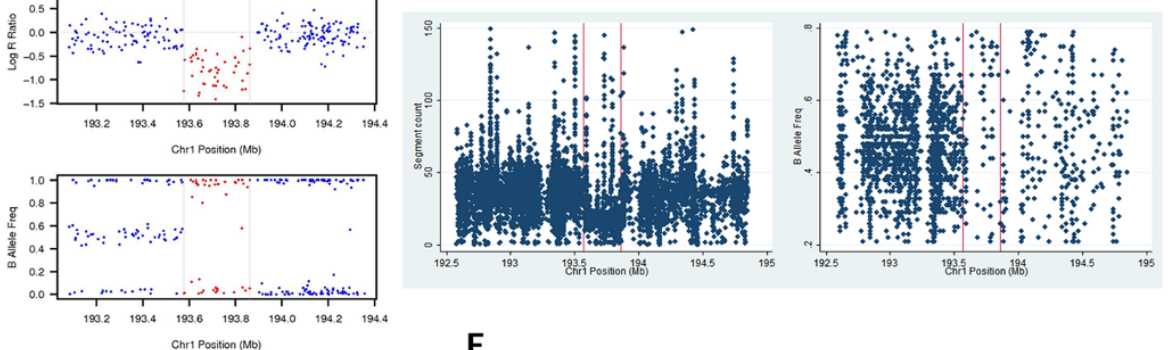

D
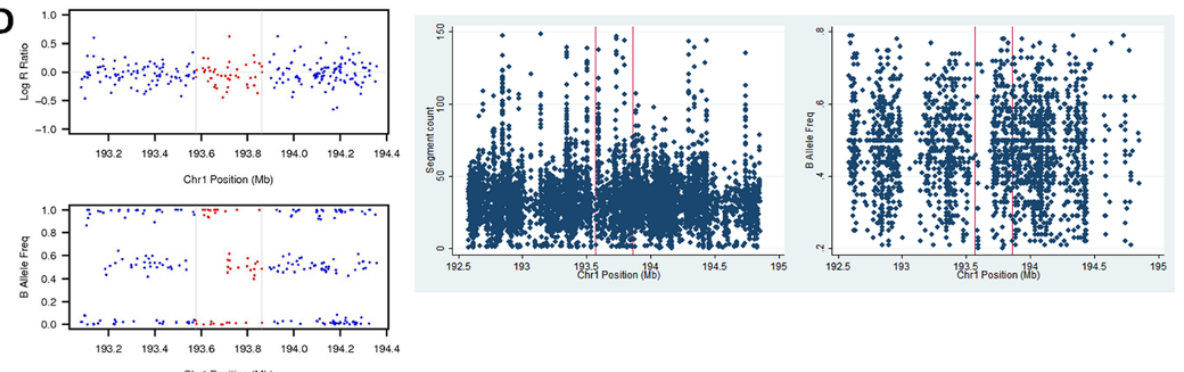

Figure 1 Analysis of copy number variations (CNVs) in the family with autism. (A) The five inherited CNVs inferred from SNP arrays are depicted with family structure, but none of the CNVs segregate with disease status. (B) Signal intensity (Log R Ratio and B Allele Frequency) plot from SNP arrays validates the 1q31 deletion in sample 10. In the deletion (dots between the two vertical lines), Log R Ratio values for SNP markers drop, and B Allele Frequency values cluster around 0 or 1. (C) PennCNV-Seq signal (sequence count and B Allele Frequency) plot on WGS data validates the 1q31 deletion in sample 10. In the deletion, the sequence counts tend to be lower than neighboring regions, and very few $B$ Allele Frequency values cluster around 0.5. (D) Signal intensity plot from SNP arrays did not indicate the presence of the 1 q31 deletion in sample 8. (E) PennCNV-Seq signal on WGS data did not indicate the presence of a 1q31 deletion in sample 8.

version 1.7 developed by CG as previously reported [28]. Each variant was assigned a quality score, which was calculated as $10 * \log _{10}[\mathrm{P}($ call is true $) / \mathrm{P}($ call is false $)]$, representing the confidence in the call. We removed variants that do not pass the default quality filter, including homozygous calls with quality scores $<20$, or heterozygous calls with quality scores $<40$. The variants passing the QC threshold were used for downstream analysis.

\section{SNP genotyping}

All genome-wide SNP genotyping for the family was performed using the Illumina HumanHap550 BeadChip at the Center for Applied Genomics at the Children's
Hospital of Philadelphia. Standard data normalization procedures and canonical genotype clustering files provided by Illumina were used to process the genotyping signals and generate genotype calls.

\section{CNV calling}

The Log R Ratio and B Allele Frequency measures for all markers for all samples were directly calculated and exported from the Illumina BeadStudio software. The CNV calls were generated using PennCNV (version 2009Aug27) [29], which utilizes an integrated hidden Markov model (HMM) that incorporates multiple sources of information, including total signal intensity 
and allelic intensity ratio at each SNP marker, the distance between neighboring SNPs, and the allele frequency of SNPs. Family information was not used in $\mathrm{CNV}$ calling. The default program parameters, library files, and the genomic wave adjustment routine [30] in the detect_cnv.pl program were used in generating CNV calls. The scan_region.pl program in PennCNV was used to map called CNVs to specific genes and exons, using the RefSeq gene definitions.

We excluded sparse CNV calls, that is, those $\mathrm{CNV}$ calls with average inter-marker distance $>50 \mathrm{~kb}$ (the average distance is approximately $5 \mathrm{~kb}$ across the whole-genome for the arrays that we used). Furthermore, we excluded all CNV calls whose genomic span overlap with known immunoglobulin regions (chr22:20715572-21595082, chr14:105065301-106352275, chr2:88937989-89411302, chr14:21159897-22090937) was $>50 \%$, as these CNVs may be a result of somatic changes. In addition, we excluded CNV calls whose genomic span overlap with centromeres (a list of genomic coordinates for centromeres in human genome NCBI 36 build were given at the PennCNV website FAQ section) was also $>50 \%$. The final set of CNV calls encompassing more than or equal to 10 SNP markers were then used in our inheritance analysis.

We also applied a recently published method, ERDS (Estimation by Read Depth with SNVs) version 1.06.04 [31], to generate CNV calls from the sequence data. We first used the Complete Genomics Analysis Tools (http://cgatools.sourceforge.net/) to generate BAM files from CG-provided map files. ERDS starts from read depth information inferred from BAM files, but also integrates other information including paired end mapping and soft-clip signature, to call CNVs sensitively and accurately. Since ERDS models deletions and duplications differently, we collected deletions $>10 \mathrm{~kb}$ and duplications $>200 \mathrm{~kb}$, with a confidence score $>300$, as a set of highly confident CNV calls. Furthermore, we used a preliminary version of PennCNV-Seq to leverage whole-genome sequence data to validate the CNV calls from SNP arrays. We developed custom scripts to process the BAM file and generated two signal intensity measures: sequence count and B Allele Frequency. Sequence count refers to the normalized sequence read on either a single SNV or as the average across a continuous segment of genomic positions without SNVs, and this measure can be directly counted from SAMtools pileup output. B Allele Frequency refers to the fraction of reads supporting non-reference alleles at a given SNV, and this measure can be calculated from aligned alleles at each position with a SNV call. For 1-copy deletions, one would expect to see decreased sequence count and the general lack of clustering of B Allele
Frequency around 0.5, compared to neighboring regions without deletions.

\section{Validation by Sanger sequencing}

Selected putative variants were examined among all family members using Sanger sequencing methods. Given the position of variants, the PCR primers were designed to encompass the candidate position, ensuring that common SNPs are not covered by the primers. The ABI Prism 3500 sequencer was used for sequencing, and the resulting ".AB1 files were loaded into the ABI Sequence Scanner version 1.0 for further analysis and genotype calling. All sequence traces were manually reviewed to ensure the reliability of the genotype calls.

\section{Variant annotation and prioritization}

We used the ANNOVAR software [32] for variant annotation, analysis, and filtering. Besides gene-based annotation, we used a custom 'variants reduction' pipeline to identify a list of candidate genes with the following criteria: (1) identify variants causing splicing or proteincoding changes, including stop loss and stop gain variants; (2) remove variants with minor allele frequency (MAF) $>1 \%$ in the 1000 Genomes Project April 2012 release; (3) remove variants with MAF $>1 \%$ in the NHLBI5400 Exomes (European Americans or African Americans); (4) remove variants with MAF $>1 \%$ in the CG46 database compiled from unrelated individuals sequenced by the Complete Genomics platform; and (5) requiring a recessive mode of inheritance, with at least two deleterious mutations found in each proband.

Additionally, we also used an alternative analytical strategy that attempts to identify any predicted deleterious variants shared by two probands with autism, regardless of disease models or family segregation patterns. We used wANNOVAR [33] (http://wannovar. usc.edu) to process this list of variants, and specified the following criteria in the website: (1) SIFT scores $<0.05$; (2) PolyPhen scores $>0.85$; and (3) GERP ++ scores $>2.0$. These are the default thresholds recommended by the developers. The final list of variants and genes are manually examined to identify any prior association with autism or other neurodevelopmental disorders.

To extend the analysis to non-coding variants, we used another custom 'variants reduction' pipeline using the ANNOVAR software with the following criteria: (1) identify variants that do not target canonical splicing sites and protein-coding regions; (2) remove variants with minor allele frequency (MAF) $>1 \%$ in the $1000 \mathrm{Ge}-$ nomes Project April 2012 release, or the NHLBI-5400 Exomes (European Americans or African Americans), or the CG46 database; (3) identify subset of variants that target evolutionarily constrained regions, defined as being located within a GERP++ conserved element with 
GERP++ scores $>2$ [34]; and (4) identify subset of variants that target 'active promoter' (state 1 inferred by chromHMM [35]) or 'strong enhancer' (state 4 and 5 inferred by chromHMM [35]) sites. Given that the nine ENCODE cell lines analyzed by chromHMM do not include a neuronal cell line, we used the data from GM12878 (Epstein-Barr Virus transformed lymphoblastoid cell line), as lymphoblastoid cell lines are used in many gene expression profiling studies on mental disorders.

\section{Haplotype analysis}

We performed haplotype sharing analysis on the pedigree, to identify genomic regions that have an identityby-descent (IBD) score of 2 between the two affected subjects. Additionally, in an exploratory analysis, we identified regions with IBD score of 0 or 1 between affected and unaffected siblings. We used the Merlin software [36] to perform haplotype phasing on the SNP genotyping data with best estimates of haplotype transmission patterns. We then used a custom script to identify genomic regions that satisfy the user-supplied IBD criteria.

\section{Results}

\section{CNV analysis on the pedigree}

We previously performed whole-genome genotyping on the pedigree, including parents and seven children (DNA samples for subject 9 is not available), using the Illumina HumanHap550 SNP genotyping arrays [6]. Given the availability of signal intensity data from the SNP arrays, we generated copy number variant (CNV) calls (see Methods).

We detected three CNVs in the father and two CNVs in the mother of potential clinical relevance, respectively (Table 1, Figure 1A). Among them, two encompassed genes and both CNVs are inherited from the mother to the offspring. A $50.7 \mathrm{~kb}$ duplication on 13q12.13 was detected in the mother and four children. The duplication disrupts the WASF3 (WAS protein family, member 3) gene, which encodes a member of the Wiskott-Aldrich

Table $1 \mathrm{~A}$ list of CNV calls encompassing >10 SNPs in the pedigree

\begin{tabular}{|c|c|c|c|c|c|c|c|}
\hline Region (hg18 coordinate) & \#SNP & Length & Type & ID & Start & End & Relationship \\
\hline chr1:193577075-193861997 & 44 & 284,923 & del & 10 & rs1359381 & rs12745696 & Offspring \\
\hline chr1:193577075-193861997 & 44 & 284,923 & del & 4 & rs1359381 & rs12745696 & Offspring \\
\hline chr1:193577075-193861997 & 44 & 284,923 & del & 2 & rs1359381 & rs12745696 & Father \\
\hline chr13:26048387-26099109 & 10 & 50,723 & dup & 7 & rs2133814 & rs7986966 & Offspring \\
\hline chr13:26048387-26099109 & 10 & 50,723 & dup & 10 & rs2133814 & rs7986966 & Offspring \\
\hline chr13:26048387-26099109 & 10 & 50,723 & dup & 6 & rs2133814 & rs7986966 & Offspring \\
\hline chr13:26048387-26099109 & 10 & 50,723 & dup & 8 & rs2133814 & rs7986966 & Offspring \\
\hline chr13:26048387-26099109 & 10 & 50,723 & dup & 1 & rs2133814 & rs7986966 & Mother \\
\hline chr2:41082092-41099005 & 11 & 16,914 & del & 6 & rs12474136 & rs2373974 & Offspring \\
\hline chr2:41082092-41099005 & 11 & 16,914 & del & 8 & rs12474136 & rs2373974 & Offspring \\
\hline chr2:41082092-41099005 & 11 & 16,914 & del & 3 & rs12474136 & rs2373974 & Offspring \\
\hline chr2:41082092-41099005 & 11 & 16,914 & del & 2 & rs12474136 & rs2373974 & Father \\
\hline chr8:3753745-3763223 & 14 & 9,479 & del & 5 & rs2930372 & rs1464619 & Offspring \\
\hline chr8:3753745-3763223 & 14 & 9,479 & del & 7 & rs2930372 & rs1464619 & Offspring \\
\hline chr8:3753745-3763223 & 14 & 9,479 & del & 4 & rs2930372 & rs1464619 & Offspring \\
\hline chr8:3753745-3763223 & 14 & 9,479 & del & 6 & rs2930372 & rs1464619 & Offspring \\
\hline chr8:3753745-3763223 & 14 & 9,479 & del & 8 & rs2930372 & rs1464619 & Offspring \\
\hline chr8:3753745-3763223 & 14 & 9,479 & del & 3 & rs2930372 & rs1464619 & Offspring \\
\hline chr8:3753745-3763223 & 14 & 9,479 & del & 1 & rs2930372 & rs1464619 & Mother \\
\hline chrX:22775615-22833684 & 14 & 58,070 & del & 5 & rs7889437 & rs5970944 & Offspring \\
\hline chrX:22775615-22833684 & 14 & 58,070 & del & 7 & rs7889437 & rs5970944 & Offspring \\
\hline chrX:22775615-22833684 & 14 & 58,070 & del & 4 & rs7889437 & rs5970944 & Offspring \\
\hline chrX:22775615-22833684 & 14 & 58,070 & del & 3 & rs7889437 & rs5970944 & Offspring \\
\hline chrX:22775615-22833684 & 14 & 58,070 & del & 2 & rs7889437 & rs5970944 & Father \\
\hline
\end{tabular}


syndrome protein family. The encoded protein forms a multiprotein complex that links receptor kinases and actin, and is involved in the transmission of signals from tyrosine kinase receptors and small GTPases to the actin cytoskeleton [37]. The WASF3 gene appears to have the highest expression in brain [38]. A $9.5 \mathrm{~kb}$ deletion on 8p23.2 in six children and the mother is located in the intronic region of the CSMD1 (CUB and Sushi multiple domains 1) gene. A previous report suggests that CSMD1 may be an important regulator of complement activation and inflammation in the developing central nervous system [39]. The other three transmitted $\mathrm{CNVs}$ do not disrupt protein coding regions. However, none of the five CNVs segregate with disease status (Figure 1A), although we cannot exclude the possibility that they may still increase the susceptibility to autism with weak effects. On the other hand, we were not able to identify any de-novo CNVs in this family with the array platform that we used, further suggesting that large de-novo CNVs are unlikely to be the major cause of autism in this multiplex pedigree. Furthermore, we stress that a de-novo $\mathrm{CNV}$ is not by any means both necessary and sufficient to cause a disease in any particular individual, as such CNVs have variable expressivity and they are moderated by the genetic background and the environment in each particular family.

\section{Whole-genome sequencing identifies a prioritized list of candidate genes}

We selected two probands in the family for nextgeneration whole-genome sequencing by Complete Genomics (CG) with over 50X coverage. In total, we identified 3,811,318 variants (including 3,396,697 SNPs) in proband 1 (ID: 10) and 3,767,904 variants (including $3,365,158$ SNPs) in proband 2 (ID: 8 ), respectively (Additional file 1: Table S1). We next compared these variants to those generated from the Illumina SNP arrays: the concordance rates for proband 1 and 2 were 99.3\% and 99.2\%, respectively, suggesting the high quality of the sequence data. These high rates of concordance were similar to other published studies using the CG platform $[28,40,41]$.

Given the availability of sequence data, we next explored two methods to generate CNV calls and validate calls from SNP arrays. We first converted the alignment files provided by CG into BAM files, and generated CNV calls using the ERDS software [31]. The CNV calls from SNP arrays can be validated in sequence data, with potentially higher resolution: for example, the boundaries for 1q31.1 deletion (285 kb on SNP array) and $13 \mathrm{q} 12$ duplication (51 kb on SNP array) on sample 10 were refined to be chr1: 193574801-193871200 (296kb) and chr13: 26049001-26110000 (61kb), respectively. The list of highly confident $\mathrm{CNV}$ calls shared by the two probands is given in Additional file 1: Table S2. Next, we developed a custom pipeline (PennCNV-Seq) to convert BAM files into quantitative measures as 'sequence count' and 'B Allele Frequency', similar to measures on SNP arrays. The presence (Figure $1 B, C$ ) or absence (Figure $1 D, E$ ) of CNVs in the two probands can be visually validated by these two quantitative measures, but the data appear to be extremely noisy, highlighting the challenge to generate reliable CNV calls from whole-genome sequencing data.

To identify potentially deleterious mutations from both probands, we next performed variant annotation and prioritization using the ANNOVAR software [32]. Our goal is to identify a list of variants/genes that are likely to be disease causal, and then assess the variant transmission patterns across the pedigree. We used a custom 'variants reduction' pipeline on these two genomes, which is composed of a series of procedures (Figure 2). For example, these include removing variants observed in several public databases that compile variant frequency information from large-scale sequencing studies. Similar to a previous study [42], we emphasize here that dbSNP is not used in the filtering procedure, since this database does not contain allele frequency information for the vast majority of SNPs and some disease causal variants may be present in dbSNP. About 500 variants were prioritized to be potentially deleterious using this pipeline in each proband. We next imposed a recessive model, requiring that each gene must contain two deleterious mutations (homozygous or compound heterozygous) to be declared as a putative contributory gene. We implemented a recessive model, because the parents are both unaffected and the phenotype distribution in the siblings is consistent with a recessive model, with $2 / 8$ (25\%) of the children being affected. This analysis resulted in 22 and 23 candidate genes in the two children with autism, respectively. Seven of these genes are shared by the two siblings, closely matching the expectation that $25 \%$ of genomic region is identical between siblings (Figure 2).

Among these candidate genes, FLG (filaggrin) encode an intermediate filament-associated protein that aggregates keratin intermediate filaments in mammalian epidermis [43]. Mutations in this gene are known to cause ichthyosis vulgaris and atopic eczema [44,45]. TCHH (trichohyalin) encodes a protein that forms multiple complex cross-links with itself and with other structural proteins, to confer mechanical strength to the hair follicle inner root sheath and to other toughened epithelial tissues [46]. NOTCH2 (neurogenic locus notch homolog protein 2) encodes a single pass transmembrane protein belonging to an evolutionarily conserved $\mathrm{NOTCH}$ receptor family. Mutations in NOTCH2 have been associated with several developmental diseases. NOTCH2 
mutations are found in about 1\% of the cases of Alagille syndrome [47], a severe developmental disorder defined clinically by hepatic bile duct paucity and cholestasis in association with cardiac, skeletal, and ophthalmologic manifestations. Mutations in $\mathrm{NOTCH} 2$ can also cause the Hajdu-Cheney syndrome [48], a disorder of severe and progressive bone loss. Additionally, truncating mutations in the last exon of $\mathrm{NOTCH} 2$ can cause a rare skeletal disorder with osteoporosis [49]. TCHHL1 (trichohyalin-like 1) has unknown function, but it shared high sequence similarity with TCHH. EMG1 (Essential for Mitotic Growth 1) encodes an essential, conserved eukaryotic protein involved in ribosome biogenesis [50]. Mutations in EMG1 have been previously associated with Bowen-Conradi syndrome, a lethal autosomal recessive disorder [51]. PCNT (pericentrin) encodes a protein that is expressed in the centrosome and is an integral component of the pericentriolar material [52]. Mutations in this gene can cause primordial dwarfism [53]. HRNR (hornerin) encodes a component of the epidermal cornified cell envelopes [54], and this gene has been linked with atopic dermatitis (AD) susceptibility in a genome-wide association study [55]. None of these genes are well recognized candidate genes previously associated with autism; however, this is not surprising given some predictions that perhaps approximately
1,000 genes will contribute in some way to the autism spectrum disorders [18-21,24,56].

\section{Shared haplotype analysis trims down candidate genes}

Given the availability of whole-genome SNP genotype data, we next performed haplotype analysis on the pedigree, to assess the utility of using allele sharing information to reduce candidate genes/regions. The goal in this analysis is to identify regions that have IBD (identity-bydescent) $=2$ in the two affected children, that is, genomic regions that are identically inherited from parents between the two affected children. In theory, only $25 \%$ of the genome should have IDB $=2$ between the two probands. Using SNP genotype data, we identified 126 genomic regions that fit this criterion, with a total size of $593 \mathrm{Mb}$. Furthermore, assuming that regions with IBD = 2 have high penetrance for autism and are far less likely to be observed in unaffected siblings, we identified a subset of genomic regions that have IBD $=0$ or IBD $=1$ between each proband and all other unaffected siblings. This procedure further reduced candidate regions to 27 regions totaling $115 \mathrm{Mb}$ (Table 2). However, we recognize that the latter hypothesis is likely too restrictive, as complex diseases such as autism may behave in polygenic fashion $[57,58]$, that is, true disease causal genes can still be present in $\mathrm{IBD}=2$ regions in 
Table 2 Genomic regions where the two probands have identical by descent (IBD) of 2, but have IBD of 0 or 1 with all other five unaffected siblings

\begin{tabular}{|c|c|c|c|c|c|c|}
\hline Chromosome & Start & End & \#SNP & Length & Start SNP & End SNP \\
\hline 1 & $24,685,742$ & $25,641,524$ & 174 & 955,783 & rs195704 & rs10903129 \\
\hline 1 & $111,171,895$ & $111,330,302$ & 39 & 158,408 & rs343769 & rs947633 \\
\hline 1 & $111,345,660$ & $118,691,338$ & 1,454 & $7,345,679$ & rs12038954 & rs7535961 \\
\hline 1 & $118,704,719$ & $143,649,677$ & 333 & $24,944,959$ & rs10923556 & rs2500347 \\
\hline 1 & $144,148,243$ & $144,975,558$ & 40 & 827,316 & rs2236566 & rs 12122100 \\
\hline 1 & $156,202,557$ & $165,715,016$ & 2,338 & $9,512,460$ & rs16839492 & rs7518703 \\
\hline 1 & $201,467,879$ & $204,068,495$ & 606 & $2,600,617$ & rs6672661 & rs1361754 \\
\hline 1 & $204,074,127$ & $214,016,229$ & 2,022 & $9,942,103$ & rs954206 & rs7549052 \\
\hline 2 & $143,712,980$ & $143,772,718$ & 16 & 59,739 & rs4371294 & rs12328672 \\
\hline 3 & $71,274,040$ & $71,332,365$ & 26 & 58,326 & rs4677532 & rs7374975 \\
\hline 3 & $188,567,203$ & $189,810,377$ & 350 & $1,243,175$ & rs6797770 & rs3732909 \\
\hline 3 & $189,812,552$ & $191,786,499$ & 536 & $1,973,948$ & rs9824282 & rs6444435 \\
\hline 5 & $179,518,398$ & $179,998,061$ & 106 & 479,664 & rs6897922 & rs4700745 \\
\hline 5 & $180,003,882$ & $180,623,543$ & 95 & 619,662 & rs11960332 & rs1279912 \\
\hline 8 & $13,440,994$ & $15,451,587$ & 1,070 & $2,010,594$ & rs1160220 & rs919401 \\
\hline 8 & $15,464,497$ & $17,859,195$ & 885 & 2,394,699 & rs12547525 & rs208753 \\
\hline 8 & $17,881,369$ & $18,740,036$ & 391 & 858,668 & rs10503606 & rs6982585 \\
\hline 10 & $53,836,193$ & $58,170,063$ & 976 & $4,333,871$ & rs11001909 & rs10825864 \\
\hline 10 & $58,698,423$ & $63,455,095$ & 941 & $4,756,673$ & rs2393230 & rs10821944 \\
\hline 10 & $109,396,522$ & $114,694,771$ & 1,012 & $5,298,250$ & rs11193576 & rs17746916 \\
\hline 12 & $14,293,625$ & $17,541,979$ & 550 & $3,248,355$ & rs17834211 & rs1553115 \\
\hline 12 & $17,545,101$ & $28,831,294$ & 2,813 & $11,286,194$ & rs10840729 & rs7311230 \\
\hline 12 & $130,049,943$ & $132,288,869$ & 432 & $2,238,927$ & rs7135850 & rs7975069 \\
\hline 13 & $59,004,926$ & $61,882,091$ & 525 & $2,877,166$ & rs1622710 & rs11838572 \\
\hline 13 & $62,305,059$ & $66,409,431$ & 620 & $4,104,373$ & rs9598515 & rs9540948 \\
\hline 13 & $66,611,634$ & $73,911,046$ & 1,636 & $7,299,413$ & rs7336017 & rs9573384 \\
\hline 13 & $73,937,508$ & $77,639,621$ & 839 & $3,702,114$ & rs9318278 & rs2254690 \\
\hline
\end{tabular}

unaffected siblings without manifesting disease phenotypes. This analysis should therefore be regarded as an exploratory analysis to reduce the number of candidate genes to be assessed.

With the above analysis, we found that $\mathrm{NOTCH} 2$ (neurogenic locus notch homolog protein 2) is the only gene among the seven candidates that fall within the 27 candidate regions. Sanger sequencing confirmed that the two probands share a R2047W mutation in exon 34 and D1327G in exon 24 of NOTCH2. However, while $\mathrm{R} 2047 \mathrm{~W}$ is present in the father, both parents appear to carry the D1327G mutation. Additional sequencing revealed that both subject 4 and subject 5 also carry the two variants. Further analysis showed that the D1327G mutation has already been documented in dbSNP (rs61752484), and it has allele frequency of $0.27 \%$ and $0.47 \%$ in 1000 Genomes Project and NHLBI-ESP 5400 exomes, respectively. It was not predicted to be deleterious by SIFT (score $=0.4$ ) [59] and PolyPhen (score = 0.07) [60]. Therefore, D1327G does not represent a variant that is private or deleterious to the family.

\section{Alternative approaches to assess shared candidate variants}

We also attempted a different analytical strategy, considering that the analytical procedures described above make strong assumptions on disease mode of inheritance (recessive disease) and the extent of haplotype sharing (IBD $=2$ between probands and IBD $<2$ between probands and unaffected siblings). Instead, prior to implementing the recessive model of inheritance in the last step of Figure 2, we were left with a large collection of rare variants (approximately 500 in each proband) that may be responsible for the autistic phenotype observed in two members of the 
family. Two hundred of these variants are shared by the two probands, and we directly assessed the likelihood that each variant would be deleterious. Our assumption was that one or several highly penetrant variants in this list could contribute to the pathogenesis of autism in a dominant fashion, and that these variants will not be $100 \%$ penetrant so they could still be present in the parents or other unaffected siblings as well.

We submitted this list of variants to wANNOVAR [33], which is a web server that provides a simple and intuitive interface to help users determine the functional significance of variants from high-throughput sequencing data. In addition to allele frequency based filtering to detect rare variants, the wANNOVAR also provides functional prediction scores such as SIFT scores [59], PolyPhen scores [60], PhyloP scores [61], and GERP++ scores [34], to help users determine the functional significance of specific genetic variants. We identified 59 variants that were concordantly predicted as deleterious by SIFT (score <0.05), PolyPhen (score $>0.8)$, and GERP $++($ score $>2)$ or without predictions. These include three splicing variants, six frameshift mutations, and 50 non-synonymous variants (Additional file 1: Table S3).

We next attempted to further trim down this list of candidate genes, by using prior biological knowledge. Manual examination of the list of genes did not identify any candidate genes that were previously reported in genetic association studies for autism, or were suspected candidate genes for autism. Therefore, we used the DAVID server [62] for functional annotation of these genes, including gene ontology assignment, SwissPro keywords, BioCarta/KEGG pathways, and OMIM association. Among this list of genes, PTK2B, ANK3, MYO7A are involved in neuron differentiation and development based on Gene Ontology. DCTN1 is associated with neuropathy, amyotrophic lateral sclerosis and Perry syndrome based on OMIM. MYO7A is associated with deafness and other neurosensory disorders based on OMIM. Among this prioritized list of genes, the most interesting one is ANK3 (Ankyrin 3). Several genomewide association studies for bipolar disorder (BD) have found a strong association of the ANK3 gene [63,64]. More recently, missense mutations in $A N K 3$ were identified in four out of 67 patients with ASDs in an exome and candidate gene sequencing study [65], and have been identified in another study that sequenced balanced chromosomal abnormalities in patients with autism or related neurodevelopmental disorders [23]. The ANK3 protein contains two well recognized domains: Ankyrin repeat-containing domain and DEATH domain. The c.11068G > A (p.G3690R) mutation observed in our study is located at the C-terminal end of this large protein, but it does not disrupt either domain. Nevertheless, the variant is located in a large genomic region that is highly conserved across 28 vertebrate species (Figure 3A), suggesting strong evolutionary constraint on the variant. Among the unaffected siblings, only subject 6 shares this variant (Figure 3B).

\section{Extending to non-coding variants}

Our analysis above made the strong assumption that all autism contributory variants in this family might be located in protein coding regions. However, recent largescale studies such as ENCODE [66] and Roadmap Epigenomics [67] have reinforced an important role for non-coding variants in regulating gene expression and function genome-wide, suggesting that some non-coding variants may also cause diseases with major effects [68]. Compared to previously published autism sequencing studies, one unique aspect of our study is the availability of whole-genome data, so we extended our analysis to non-coding variants. Given that $>99 \%$ of the variants in whole-genome sequence data are non-coding and that functional prediction algorithms for non-coding variants are far less well developed than coding variants, the data analysis is expected to be much more challenging.

Nevertheless, we used an analytical procedure aimed to significantly reduce the candidate list and focus on variants that are most likely to be relevant to autism pathogenesis. For each proband, similar to above, we first removed variants that are found in three public databases (1000 Genomes Projects, NHLBI-ESP5400, CG46) with MAF $>1 \%$. This resulted in a reduced list of 46,224 noncoding rare variants that are shared between the two probands, which is still more than even the whole-exome variants without any filtering. Next, we attempted to use functional prediction approaches that leverage computational and experimental evidence to prioritize noncoding variants. From the candidate pool, we identified a list of 1,096 variants that are located within GERP++ conserved elements and have GERP ++ scores [34] $>2$, which represent genomic sites that are under strong selective constraint by computational means. Furthermore, we used the ENCODE experimental data to retrieve variants that are located in 'active promoters' or 'strong enhancers' as predicted by chromHMM [35]. Previous studies demonstrated that disease-associated SNPs are significantly more likely to coincide with the predicted 'strong enhancers' [35]. In total, we identified 14 variants located in active promoters and 19 variants located in strong enhancers (Additional file 1: Table S4). Two examples are illustrated (Figure 4). COQ5 encodes a methyltransferase based on studies in yeast [69]. The intergenic variant upstream of COQ5 is also highly conserved, and is located within ENCODE H3K4Me1 (enhancer/promoter-associated) and H3K4Me3 (promoterassociated) peaks and DNase I hypersensitivity site 


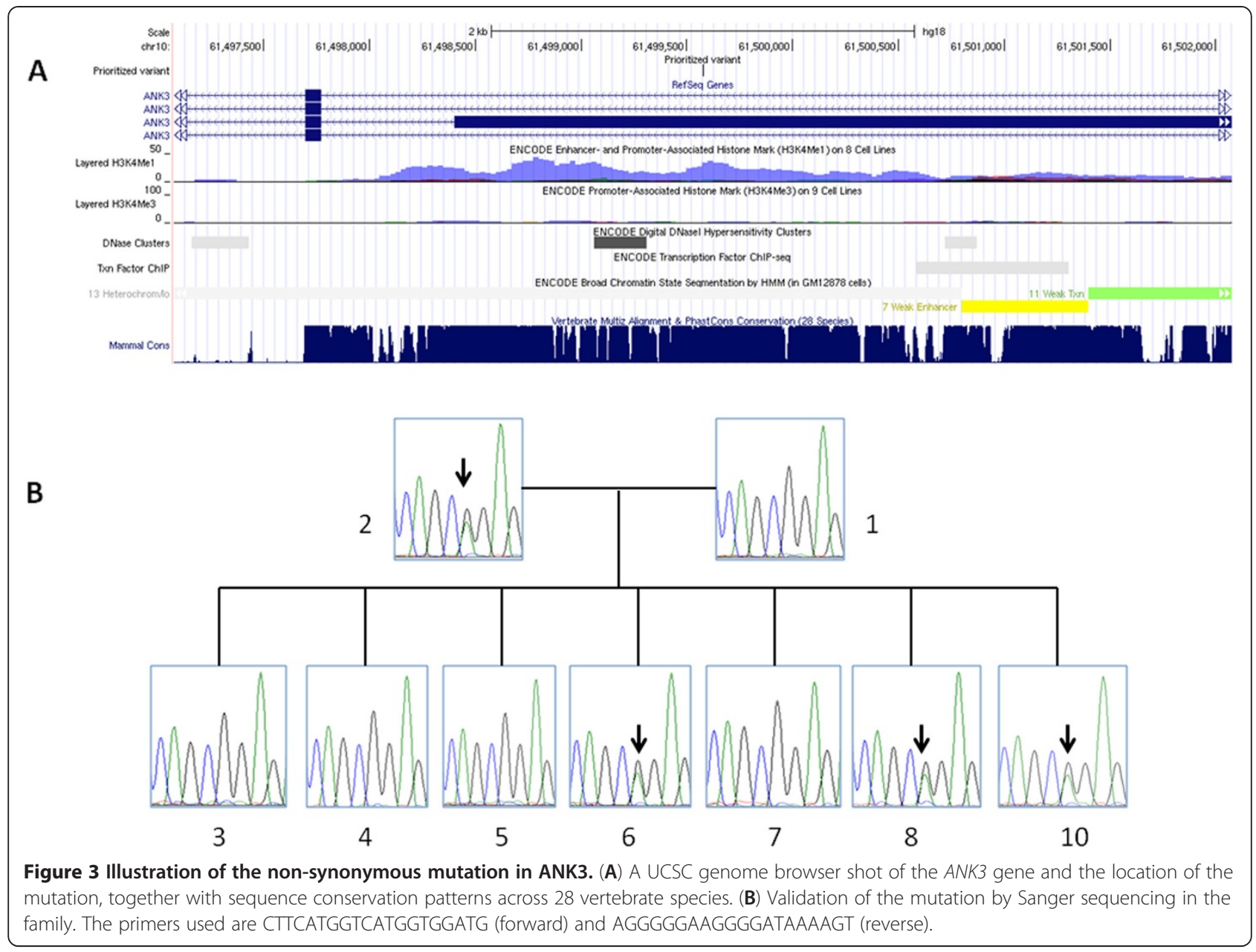

(Figure 4A). SMG6 encodes a protein that participates in the nonsense-mediated mRNA decay (NMD) pathway [70], and it was recently identified as an autism candidate gene by sequencing balanced chromosomal abnormalities in patients with autism or related neurodevelopmental disorders [23]. A prioritized intronic variant is located in a region of SMG6 that is predicted to be a 'strong enhancer', is highly conserved across 28 vertebrate species, and is located in ENCODE H3K4Me1 (enhancer/promoterassociated) peaks and DNase I hypersensitivity sites (Figure 4B).

\section{Discussion}

In this study, we performed a pilot sequencing analysis aimed at identifying potential genetic risk factors for autism in a large pedigree, focusing on inherited mutations. We attempted multiple complementary analytical approaches, each of which identified one to a few candidate genes. We were not able to confirm specific disease-causing mutations with certainty, but we uncovered multiple rare mutations unique to the family, as well as several candidate genes that harbor suspected deleterious coding or non-coding mutations. Among them, based on prior literature, ANK3 is a highly plausible candidate gene that may increase the susceptibility to ASDs in this family. Given that autism is a complex neuropsychiatric disease, it is likely that multiple contributing variants in the family may increase susceptibility; therefore, even if a specific candidate gene does contribute to disease risk, we caution that a single candidate gene may not be entirely responsible (that is, necessary and sufficient) for the genetic risk of autism in this pedigree. Although our findings are restricted to this specific family, these new candidates can certainly be evaluated in future sequencing studies to establish their true relevance to autism susceptibility.

We applied a whole genome sequencing strategy to reveal specific genetic mutations that may confer susceptibility to ASDs in one single family, and these results can also be compared to exome sequencing studies on schizophrenia, ADHD, and other neurodevelopmental disorders. A recent study revealed that de-novo mutation rate might play a major role in schizophrenia, and a large excess of nonsynonymous changes were identified by whole exome 


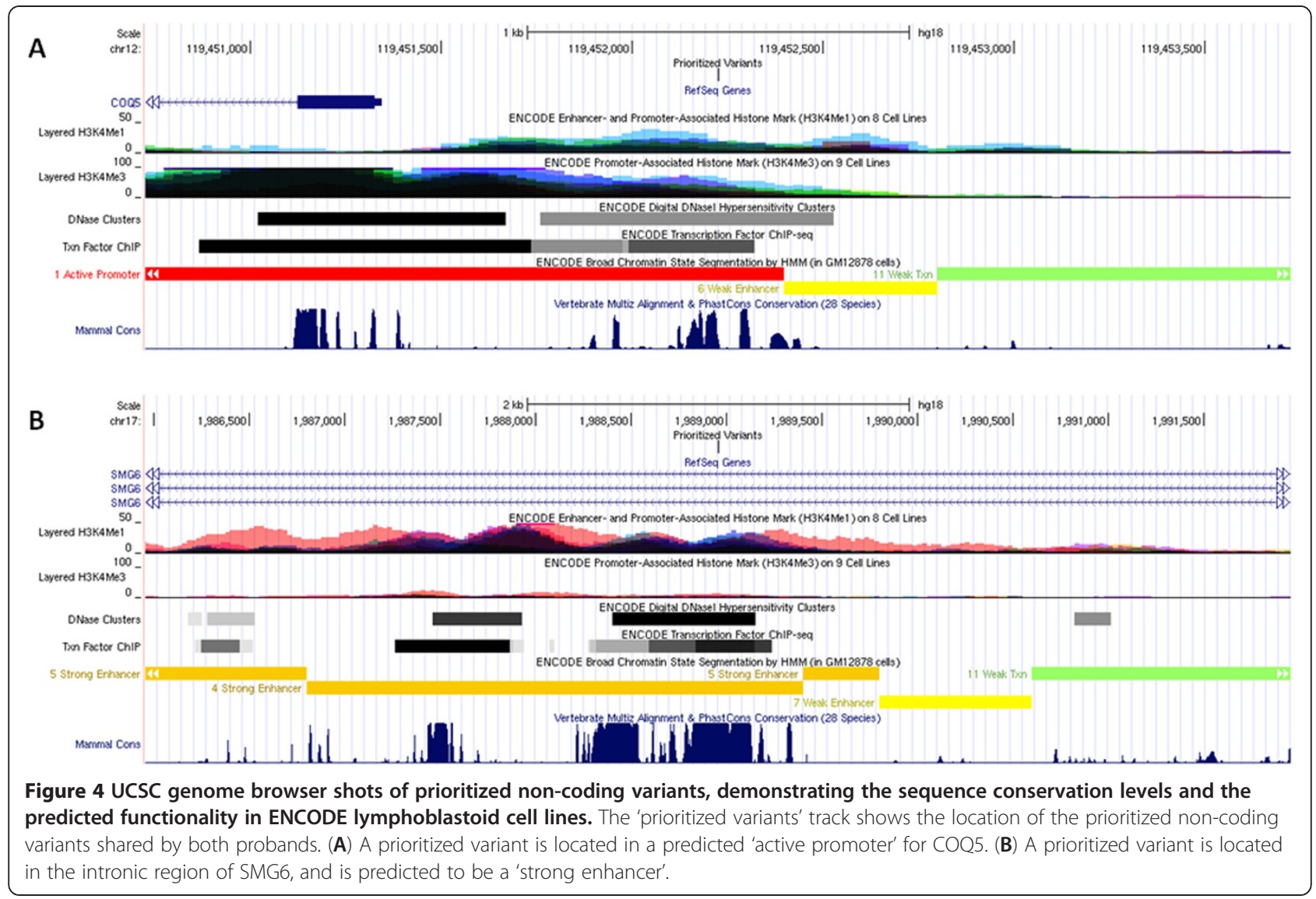

sequencing from 53 sporadic cases, 22 unaffected controls, and their parents [71]. In another study on schizophrenia, four of the 15 identified de-novo mutations in eight probands were nonsense mutations [72]. In a previous smallscale exome sequencing study screening attention deficit/ hyperactivity disorder (ADHD) genes on a multiplex pedigree, multiple rare coding variants were identified but were not prioritized based on bioinformatics predictions [42]. In comparison, our study specifically identified rare and family-specific variants rather than de-novo mutations.

We initially focused on inherited mutations that are likely to be recessive, which shares some similarity with a very recent exome sequencing study on ASD families enriched for inherited causes due to consanguinity [24]. Other studies have focused on sporadic mutations in families where the parents have been characterized as most likely 'unaffected' with autism [17-22], and several observations support the hypothesis that the genetic basis for ASDs in sporadic cases may be different from that seen in families with multiple affected individuals, with some of the former possibly more likely to result from de-novo mutation events rather than inherited variants. For an approach complementary to ongoing exome sequencing studies aiming to detect de-novo mutations in ASDs [17-22], we specifically selected a multiplex family to test our ability to find inherited mutations that increase risk for ASDs.

In addition to finding inherited mutations, one unique aspect of our study is the use of whole-genome sequence data, which enabled us to perform exploratory analysis on non-coding variants. Given the far larger number of candidate non-coding variants than coding variants, we had to apply highly stringent filtering criteria to focus on those that are most likely to be functionally relevant. These include the use of bioinformatics predictions from evolutionary constraint [34], as well as experimental evidence from the ENCODE project [66]. As our knowledge and bioinformatics approaches for non-coding variants may improve in the future, we may be able to better interrogate the sequencing data to identify disease causal non-coding variants.

We also need to emphasize that previous studies all used the Illumina platform, yet our study used the CG platform, which represents a different type of sequencing technology [28] and generates vastly different types of output files for downstream analysis. As the Illumina platform uses open data formats, a variety of academic and commercial tools have been developed to analyze 
data from the Illumina sequencers and improve variant calls; in comparison, the CG platform takes a proprietary, 'black-box' approach, so that researchers generally have to rely on variant calls and associated quality scores provided by CG. A recent study has comprehensively compared these two platforms and identified that $12 \%$ of the called variants are discordant between platforms, yet $>60 \%$ of these discordant variants were indeed present in the genome based on Sanger validation [40]. Another recently published study also compared data from the 1000 Genomes Project and Complete Genomics, and demonstrated that $19 \%$ of the single nucleotide variants (SNVs) reported from common genomes are unique to one dataset [73]. Therefore, current sequencing studies on neuropsychiatric diseases, including ours, may all suffer significantly from false-negative variant calls, and may miss a portion of disease causal variants. Combining data from orthogonal platforms may partially reduce this problem, although this will result in higher sequencing and analytical cost.

In the current study, we first made the assumption that the ASD in the pedigree might be caused by a just a handful of mutations with high penetrance, and under such a model we were able to identify a list of possible such candidate genes. However, in practice, there may be a spectrum of diseases manifesting in each individual, with an as-yet-unknown balance of oligogenic and polygenic modes of inheritance. So, the approaches that we used were somewhat $a d h o c$, and we were unable to generate statistical support for these candidate genes. Indeed, the appropriate statistical threshold to determine functional relevance, in the context of prior biological knowledge, is not well developed. In summary, our study represents one of the first examples demonstrating the feasibility of whole genome sequencing for familial samples and analyzing inherited mutations on ASDs. Ultimately, we believe that studies focusing on de-novo or inherited mutations can complement each other, and reveal a more comprehensive picture of susceptibility to ASDs, once sufficient sample sizes have been reached by the community.

\section{Conclusion}

In conclusion, while whole-genome sequencing is a powerful discovery tool, our results demonstrate the complexity of whole-genome analysis when focusing on individual families. Although we were able to generate a list of candidate genes through several approaches, we caution that extensive functional studies are needed to identify any disease causal variants with certainty. Despite that, our analysis provides a prioritized shortlist for further association and validation studies and reflects upon the added value with large family pedigrees.

\section{Additional file}

Additional file 1: Table S1. Summary of variant calls generated from whole-genome sequence data on two probands. Table S2. A list of highly confident CNV calls generated by ERDS and shared by two probands. Conf refers to 'confidence score', and CN refers to 'copy number'. Table S3. A list of prioritized exonic/splicing variants that are shared between two probands and are predicted to be deleterious. Table S4. A list of prioritized non-coding variants that are shared between the two probands.

\section{Abbreviations}

ADHD: Attention deficit hyperactivity disorder; AGRE: Autism Genetic Resource Exchange; ASD: Autism spectrum disorder; CDC: Centers for Disease Control and Prevention; CG: Complete Genomics; CNV: Copy number variation; DEL: Deletion; DUP: Duplication; ENCODE: ENCyclopedia Of DNA Elements; ERDS: Estimation by Read Depth with SNVs; GWAS: Genomewide association study; IBD: Identity-by-descent; MAF: Minor allele frequency; NCBI: National Center for Biotechnology Information; NGS: Next-generation sequencing; NHLBI: National Heart Lung and Blood Institute; NMD: Nonsense-mediated mRNA decay; PCR: Polymerase chain reaction; SNP: Single nucleotide polymorphism; SNV: Single nucleotide variant; WES: Whole-exome sequencing.

\section{Competing interests}

The authors declare that they have no competing interests.

\section{Authors' contributions}

LS and KW carried out the data analysis, performed the literature survey, and drafted the manuscript. RG performed alignment and coverage analysis of the whole-genome sequence data, and revised the manuscript. $\mathrm{XZ}, \mathrm{MH}$, and $\mathrm{GJ}$ interpreted the results and helped with writing of the manuscript. FGO performed the Sanger sequencing validation. $\mathrm{CH}$ and $\mathrm{CK}$ performed quality control and sample handling. KW and $\mathrm{HH}$ conceived the study, guided data analysis, and revised the manuscript. All authors read and approved the final manuscript.

\section{Acknowledgements}

The authors thank members of the Wang and Hakonarson lab for helpful discussions and comments. This study is in part supported by NIH/NHGRI grant number R01 HG006465 and by PADOH grant 4100047863 for autism genetics. We also thank the Lurie Foundation and the Margaret Q Landenberger Foundation for their support.

\section{Author details}

${ }^{1}$ Department of Psychiatry, Zilkha Neurogenetic Institute, Keck School of Medicine, University of Southern California, Los Angeles, CA 90089, USA. ${ }^{2}$ School of Bioscience and Bioengineering, South China University of Technology, Guangzhou 510641, China. ${ }^{3}$ BGI Tianjin, Tianjin 300308, China. ${ }^{4}$ Center for Applied Genomics, Children's Hospital of Philadelphia, Philadelphia, PA 19104, USA. ${ }^{5}$ Stanley Institute for Cognitive Genomics, Cold Spring Harbor Laboratory, New York, NY 11724, USA. ${ }^{6}$ Department of Pediatrics, University of Pennsylvania, Philadelphia, PA 19104, USA.

Received: 4 October 2012 Accepted: 26 March 2013

Published: 18 April 2013

\section{References}

1. American Psychiatric Association, Task Force on DSM-IV: Diagnostic and statistical manual of mental disorders: DSM-IV-TR. 4th edition. Washington, DC: American Psychiatric Association; 2000.

2. Jon Baio E: Prevalence of autism spectrum disorders - autism and developmental disabilities monitoring network, 14 sites, United States, 2008. Centers Dis Contr Prev 2012, 61:1-19.

3. Ganz ML: The lifetime distribution of the incremental societal costs of autism. Arch Pediatr Adolesc Med 2007, 161:343-349.

4. Lichtenstein P, Carlstrom E, Rastam M, Gillberg C, Anckarsater H: The genetics of autism spectrum disorders and related neuropsychiatric disorders in childhood. Am J Psychiatry 2010, 167:1357-1363. 
5. Ma D, Salyakina D, Jaworski JM, Konidari I, Whitehead PL, Andersen AN, Hoffman JD, Slifer SH, Hedges DJ, Cukier HN, Griswold AJ, McCauley JL, Beecham GW, Wright HH, Abramson RK, Martin ER, Hussman JP, Gilbert JR, Cuccaro ML, Haines JL, Pericak-Vance MA: A genome-wide association study of autism reveals a common novel risk locus at 5 p14.1. Ann Hum Genet 2009, 73:263-273.

6. Wang K, Zhang H, Ma D, Bucan M, Glessner JT, Abrahams BS, Salyakina D, Imielinski M, Bradfield JP, Sleiman PM, Kim CE, Hou C, Frackelton E, Chiavacci R, Takahashi N, Sakurai T, Rappaport E, Lajonchere CM, Munson J, Estes A, Korvatska O, Piven J, Sonnenblick LI, Alvarez Retuerto Al, Herman El, Dong H, Hutman T, Sigman M, Ozonoff S, Klin A, et al: Common genetic variants on $5 \mathrm{p} 14.1$ associate with autism spectrum disorders. Nature 2009, 459:528-533.

7. Weiss LA, Arking DE, Daly MJ, Chakravarti A: A genome-wide linkage and association scan reveals novel loci for autism. Nature 2009, 461:802-808.

8. Anney R, Klei L, Pinto D, Regan R, Conroy J, Magalhaes TR, Correia C, Abrahams BS, Sykes N, Pagnamenta AT, Almeida J, Bacchelli E, Bailey AJ, Baird G, Battaglia A, Berney T, Bolshakova N, Bolte S, Bolton PF, Bourgeron T, Brennan S, Brian J, Carson AR, Casallo G, Casey J, Chu SH, Cochrane L, Corsello C, Crawford EL, Crossett A, et al: A genome-wide scan for common alleles affecting risk for autism. Hum Mol Genet 2010, 19:4072-4082

9. Anney R, Klei L, Pinto D, Almeida J, Bacchelli E, Baird G, Bolshakova N, Bolte S, Bolton PF, Bourgeron T, Brennan S, Brian J, Casey J, Conroy J, Correia C, Corsello C, Crawford EL, De Jonge M, Delorme R, Duketis E, Dugue F, Estes A, Farrar P, Fernandez BA, Folstein SE, Fombonne E, Gilbert J, Gillberg C, Glessner JT, Green A, et al: Individual common variants exert weak effects on the risk for autism spectrum disorderspi. Hum Mol Genet 2012, 21:4781-4792.

10. Glessner JT, Wang K, Cai G, Korvatska O, Kim CE, Wood S, Zhang H, Estes A, Brune CW, Bradfield JP, Imielinski M, Frackelton EC, Reichert J, Crawford EL, Munson J, Sleiman PM, Chiavacci R, Annaiah K, Thomas K, Hou C, Glaberson W, Flory J, Otieno F, Garris M, Soorya L, Klei L, Piven J, Meyer KJ, Anagnostou E, Sakurai T, et al: Autism genome-wide copy number variation reveals ubiquitin and neuronal genes. Nature 2009, 459:569-573.

11. Pinto D, Pagnamenta AT, Klei L, Anney R, Merico D, Regan R, Conroy J, Magalhaes TR, Correia C, Abrahams BS, Almeida J, Bacchelli E, Bader GD, Bailey AJ, Baird G, Battaglia A, Berney T, Bolshakova N, Bolte S, Bolton PF, Bourgeron T, Brennan S, Brian J, Bryson SE, Carson AR, Casallo G, Casey J, Chung BH, Cochrane L, Corsello C, et al: Functional impact of global rare copy number variation in autism spectrum disorders. Nature 2010, 466:368-372.

12. Sebat J, Lakshmi B, Malhotra D, Troge J, Lese-Martin C, Walsh T, Yamrom B, Yoon S, Krasnitz A, Kendall J, Leotta A, Pai D, Zhang R, Lee YH, Hicks J, Spence SJ, Lee AT, Puura K, Lehtimaki T, Ledbetter D, Gregersen PK, Bregman J, Sutcliffe JS, Jobanputra V, Chung W, Warburton D, King MC, Skuse D, Geschwind DH, Gilliam TC, et al: Strong association of de novo copy number mutations with autism. Science 2007, 316:445-449.

13. Sanders SJ, Ercan-Sencicek AG, Hus V, Luo R, Murtha MT, Moreno-De-Luca D, Chu SH, Moreau MP, Gupta AR, Thomson SA, Mason CE, Bilquvar K, Celestino-Soper PB, Choi M, Crawford EL, Davis L, Wright NR, Dhodapkar RM, DiCola M, DiLullo NM, Fernandez TV, Fielding-Singh V, Fishman DO, Frahm S, Garagaloyan R, Goh GS, Kammela S, Klei L, Lowe JK, Lund SC, et al: Multiple recurrent de novo CNVs, including duplications of the $7 q 11.23$ Williams syndrome region, are strongly associated with autism. Neuron 2011, 70:863-885.

14. Metzker ML: Sequencing technologies - the next generation. Nat Rev Genet 2010, 11:31-46.

15. Bamshad MJ, Ng SB, Bigham AW, Tabor HK, Emond MJ, Nickerson DA, Shendure J: Exome sequencing as a tool for Mendelian disease gene discovery. Nat Rev Genet 2011, 12:745-755.

16. Gilissen C, Hoischen A, Brunner HG, Veltman JA: Unlocking Mendelian disease using exome sequencing. Genome Biol 2011, 12:228.

17. O'Roak BJ, Deriziotis P, Lee C, Vives L, Schwartz JJ, Girirajan S, Karakoc E, Mackenzie AP, Ng SB, Baker C, Rieder MJ, Nickerson DA, Bernier R, Fisher SE, Shendure J, Eichler EE: Exome sequencing in sporadic autism spectrum disorders identifies severe de novo mutations. Nat Genet 2011, 43:585-589.

18. O'Roak BJ, Vives L, Girirajan S, Karakoc E, Krumm N, Coe BP, Levy R, Ko A, Lee C, Smith JD, Turner EH, Stanaway IB, Vernot B, Maliq M, Baker C, Reilly B, Akey JM, Borenstein E, Rieder MJ, Nickerson DA, Bernier R, Shendure J,
Eichler EE: Sporadic autism exomes reveal a highly interconnected protein network of de novo mutations. Nature 2012, 485:246-250.

19. Sanders SJ, Murtha MT, Gupta AR, Murdoch JD, Raubeson MJ, Willsey AJ, Ercan-Sencicek AG, DiLullo NM, Parikshak NN, Stein JL, Walker MF, Ober GT, Teran NA, Song Y, El-Fishawy P, Murtha RC, Choi M, Overton JD, Bjornson RD, Carriero NJ, Meyer KA, Bilquvar K, Mane SM, Sestan N, Lifton RP, Gunel M, Roeder K, Geschwind DH, Devlin $B$, State MW: De novo mutations revealed by whole-exome sequencing are strongly associated with autism. Nature 2012, 485:237-241.

20. Neale BM, Kou Y, Liu L, Ma'ayan A, Samocha KE, Sabo A, Lin CF, Stevens C, Wang LS, Makarov V, Polak P, Yoon S, Maguire J, Crawford EL, Campbell NG, Geller ET, Valladares O, Schafer C, Liu H, Zhao T, Cai G, Lihm J, Dannenfelser R, Jabado O, Peralta Z, Nagaswamy U, Muzny D, Reid JG, Newsham I, Wu Y, et al: Patterns and rates of exonic de novo mutations in autism spectrum disorders. Nature 2012, 485:242-245.

21. Iossifov I, Ronemus M, Levy D, Wang Z, Hakker I, Rosenbaum J, Yamrom B, Lee YH, Narzisi G, Leotta A, Kendall J, Grabowska E, Ma B, Marks S, Rodgers L, Stepansky A, Troge J, Andrews P, Bekritsky M, Pradhan K, Ghiban E, Kramer M, Parla J, Demeter R, Fulton LL, Fulton RS, Magrini VJ, Ye K, Darnell $\mathrm{RB}$, et al: De novo gene disruptions in children on the autistic spectrum. Neuron 2012, 74:285-299.

22. Kong A, Frigge ML, Masson G, Besenbacher S, Sulem P, Magnusson G, Gudjonsson SA, Sigurdsson A, Jonasdottir A, Wong WS, Sigurdsson G, Walters GB, Steinberg S, Helgason H, Thorleifsson G, Gudbjartsson DF, Helgason A, Magnusson OT, Thorsteinsdottir U, Stefansson K: Rate of de novo mutations and the importance of father's age to disease risk. Nature 2012, 488:471-475.

23. Talkowski ME, Rosenfeld JA, Blumenthal I, Pillalamarri V, Chiang C, Heilbut A, Ernst C, Hanscom C, Rossin E, Lindgren AM, Pereira S, Ruderfer D, Kirby A, Ripke S, Harris DJ, Lee JH, Ha K, Kim HG, Solomon BD, Gropman AL, Lucente D, Sims K, Ohsumi TK, Borowsky ML, Loranger S, Quade B, Lage K, Miles J, Wu BL, Shen Y, et al: Sequencing chromosomal abnormalities reveals neurodevelopmental loci that confer risk across diagnostic boundaries. Cell 2012, 149:525-537.

24. Yu TW, Chahrour MH, Coulter ME, Jiralerspong S, Okamura-Ikeda K, Ataman B, Schmitz-Abe K, Harmin DA, Adli M, Malik AN, D'Gama AM, Lim ET, Sanders SJ, Mochida GH, Partlow JN, Sunu CM, Felie JM, Rodriguez J, Nasir RH, Ware J, Joseph RM, Hill RS, Kwan BY, Al-Saffar M, Mukkades NM, Hashmi A, Balkhy S, Gascon GG, Hisama FM, LeClair E, et al: Using whole-exome sequencing to identify inherited causes of autism. Neuron 2013, 77:259-273.

25. Geschwind DH, Sowinski J, Lord C, Iversen P, Shestack J, Jones P, Ducat L, Spence SJ: The autism genetic resource exchange: a resource for the study of autism and related neuropsychiatric conditions. Am J Hum Genet 2001, 69:463-466.

26. Drmanac R, Sparks AB, Callow MJ, Halpern AL, Burns NL, Kermani BG, Carnevali P, Nazarenko I, Nilsen GB, Yeung G: Human genome sequencing using unchained base reads on self-assembling DNA nanoarrays. Science 2010, 327:78-81.

27. Roach JC, Boysen C, Wang K, Hood L: Pairwise end sequencing: a unified approach to genomic mapping and sequencing. Genomics 1995, 26:345-353.

28. Drmanac R, Sparks AB, Callow MJ, Halpern AL, Burns NL, Kermani BG, Carnevali P, Nazarenko I, Nilsen GB, Yeung G, Dahl F, Fernandez A, Staker B, Pant KP, Baccash J, Borcherding AP, Brownley A, Cedeno R, Chen L, Chernikoff D, Cheung A, Chirita R, Curson B, Ebert JC, Hacker CR, Hartlage R, Hauser B, Huang S, Jiang Y, Karpinchyk V, et al: Human genome sequencing using unchained base reads on self-assembling DNA nanoarrays. Science 2010, 327:78-81.

29. Wang K, Li M, Hadley D, Liu R, Glessner J, Grant SFA, Hakonarson H, Bucan M: PennCNV: an integrated hidden Markov model designed for high-resolution copy number variation detection in wholegenome SNP genotyping data. Genome Res 2007, 17:1665-1674.

30. Diskin SJ, Li M, Hou C, Yang S, Glessner J, Hakonarson H, Bucan M, Maris JM, Wang K: Adjustment of genomic waves in signal intensities from whole-genome SNP genotyping platforms. Nucleic Acids Res 2008, 36:e126.

31. Zhu M, Need AC, Han Y, Ge D, Maia JM, Zhu Q, Heinzen EL, Cirulli ET, Pelak K, He M, Ruzzo EK, Gumbs C, Singh A, Feng S, Shianna KV, 
Goldstein DB: Using ERDS to infer copy-number variants in highcoverage genomes. Am J Hum Genet 2012, 91:408-421.

32. Wang $\mathrm{K}, \mathrm{Li} \mathrm{M}, \mathrm{Hakonarson} \mathrm{H}$ : ANNOVAR: functional annotation of genetic variants from high-throughput sequencing data. Nucleic Acids Res 2010, 38:e164.

33. Chang $X$, Wang K: wANNOVAR: annotating genetic variants for personal genomes via the web. J Med Genet 2012, 49:433-436.

34. Davydov EV, Goode DL, Sirota M, Cooper GM, Sidow A, Batzoglou S: Identifying a high fraction of the human genome to be under selective constraint using GERP++. PLoS Comput Biol 2010, 6:e1001025.

35. Ernst J, Kheradpour P, Mikkelsen TS, Shoresh N, Ward LD, Epstein CB, Zhang X, Wang L, Issner R, Coyne M, Ku M, Durham T, Kellis M, Bernstein BE: Mapping and analysis of chromatin state dynamics in nine human cell types. Nature 2011, 473:43-49.

36. Abecasis GR, Cherny SS, Cookson WO, Cardon LR: Merlin-rapid analysis of dense genetic maps using sparse gene flow trees. Nat Genet 2002, 30:97-101.

37. Suetsugu S, Miki H, Takenawa T: Identification of two human WAVE/SCAR homologues as general actin regulatory molecules which associate with the Arp2/3 complex. Biochem Biophys Res Commun 1999, 260:296-302.

38. Su Al, Wiltshire T, Batalov S, Lapp H, Ching KA, Block D, Zhang J, Soden R, Hayakawa M, Kreiman G, Cooke MP, Walker JR, Hogenesch JB: A gene atlas of the mouse and human protein-encoding transcriptomes. Proc Natl Acac Sci U S A 2004, 101:6062-6067.

39. Kraus DM, Elliott GS, Chute H, Horan T, Pfenninger KH, Sanford SD, Foster S, Scully S, Welcher AA, Holers VM: CSMD1 is a novel multiple domain complement-regulatory protein highly expressed in the central nervous system and epithelial tissues. I Immunol 2006, 176:4419-4430.

40. Lam HY, Clark MJ, Chen R, Natsoulis G, O'Huallachain M, Dewey FE, Habegger L, Ashley EA, Gerstein MB, Butte AJ, Ji HP, Snyder M: Performance comparison of whole-genome sequencing platforms. Nat Biotechnol 2012, 30:78-82.

41. Roach JC, Glusman G, Smit AF, Huff CD, Hubley R, Shannon PT, Rowen L, Pant KP, Goodman N, Bamshad M, Shendure J, Drmanac R, Jorde LB, Hood L, Galas DJ: Analysis of genetic inheritance in a family quartet by whole-genome sequencing. Science 2010, 328:636-639

42. Lyon GJ, Jiang T, Van Wijk R, Wang W, Bodily PM, Xing J, Tian L, Robison RJ, Clement M, Lin Y, Zhang P, Liu Y, Moore B, Glessner JT, Elia J, Reimherr F, van Solinge WW, Yandell M, Hakonarson H, Wang J, Johnson $W E$, Wei $Z$, Wang $K$ : Exome sequencing and unrelated findings in the context of complex disease research: ethical and clinical implications. Discov Med 2011, 12:41-55.

43. Gan SQ, McBride OW, Idler WW, Markova N, Steinert PM: Organization, structure, and polymorphisms of the human profilaggrin gene. Biochemistry 1990, 29:9432-9440.

44. Smith FJ, Irvine AD, Terron-Kwiatkowski A, Sandilands A, Campbell LE, Zhao Y, Liao H, Evans AT, Goudie DR, Lewis-Jones S, Arseculeratne G, Munro CS, Sergeant A, O'Regan G, Bale SJ, Compton JG, DiGiovanna JJ, Presland RB, Fleckman P, McLean WH: Loss-of-function mutations in the gene encoding filaggrin cause ichthyosis vulgaris. Nat Genet 2006, 38:337-342

45. Sandilands A, Terron-Kwiatkowski A, Hull PR, O'Regan GM, Clayton TH, Watson RM, Carrick T, Evans AT, Liao H, Zhao Y, Campbell LE, Schmuth M, Gruber R, Janecke R, Elias PM, van Steensel MA, Nagtzaam I, van Geel M, Steijlen PM, Munro CS, Bradley DG, Palmer CN, Smith FJ, McLean WH, Irvine AD: Comprehensive analysis of the gene encoding filaggrin uncovers prevalent and rare mutations in ichthyosis vulgaris and atopic eczema. Nat Genet 2007, 39:650-654.

46. Steinert PM, Parry DA, Marekov LN: Trichohyalin mechanically strengthens the hair follicle: multiple cross-bridging roles in the inner root shealth. J Biol Chem 2003, 278:41409-41419.

47. McDaniell R, Warthen DM, Sanchez-Lara PA, Pai A, Krantz ID, Piccoli DA, Spinner NB: NOTCH2 mutations cause Alagille syndrome, a heterogeneous disorder of the notch signaling pathway. Am J Hum Genet 2006, 79:169-173.

48. Simpson MA, Irving MD, Asilmaz E, Gray MJ, Dafou D, Elmslie FV, Mansour S, Holder SE, Brain CE, Burton BK, Kim KH, Pauli RM, Aftimos S, Stewart H, Kim CA, Holder-Espinasse M, Robertson SP, Drake WM, Trembath RC: Mutations in NOTCH2 cause Hajdu-Cheney syndrome, a disorder of severe and progressive bone loss. Nat Genet 2011, 43:303-305.
49. Isidor B, Lindenbaum P, Pichon O, Bezieau S, Dina C, Jacquemont S, Martin-Coignard D, Thauvin-Robinet C, Le Merrer M, Mandel JL, David A, Faivre L, Cornier-Daire V, Redon R, Le Ciagnec C: Truncating mutations in the last exon of NOTCH2 cause a rare skeletal disorder with osteoporosis. Nat Genet 2011, 43:306-308.

50. Eschrich D, Buchhaupt $M$, Kotter P, Entian KD: Nep1p (Emg1p), a novel protein conserved in eukaryotes and archaea, is involved in ribosome biogenesis. Curr Genet 2002, 40:326-338.

51. Lamont RE, Loredo-Osti J, Roslin NM, Mauthe J, Coghlan G, Nylen E, Frappier D, Innes AM, Lemire EG, Lowry RB, Greenberg CR, TriggsRaine BL, Morgan K, Wrogemann K, Fujiwara TM, Zelinski T: A locus for Bowen-Conradi syndrome maps to chromosome region 12p13.3. Am J Med Genet A 2005, 132A:136-143.

52. Flory MR, Moser MJ, Monnat RJ Jr, Davis TN: Identification of a human centrosomal calmodulin-binding protein that shares homology with pericentrin. Proc Natl Acac Sci U S A 2000, 97:5919-5923.

53. Rauch A, Thiel $C T$, Schindler D, Wick U, Crow YJ, Ekici AB, van Essen AJ, Goecke TO, Al-Gazali L, Chrzanowska KH, Zweier C, Brunner HG, Becker K, Curry CJ, Dallapiccola B, Devriendt K, Dorfler A, Kinning E, Megarbane A, Meinecke P, Semple RK, Spranger S, Toutain A, Trembath RC, Voss E, Wilson $L$, Hennekam R, de Zegher F, Dorr HG, Reis A: Mutations in the pericentrin (PCNT) gene cause primordial dwarfism. Science 2008, 319:816-819.

54. Henry J, Hsu CY, Haftek M, Nachat R, de Koning HD, Gardinal-Galera I, Hitomi K, Balica S, Jean-Decoster C, Schmitt AM, Paul C, Serre G, Simon M: Hornerin is a component of the epidermal cornified cell envelopes. FASEB J 2011, 25:1567-1576.

55. Esparza-Gordillo J, Weidinger S, Folster-Holst R, Bauerfeind A, Ruschendorf F, Patone G, Rohde K, Marenholz I, Schulz F, Kerscher T, Hubner N, Wahn U, Schreiber S, Franke A, Vogler R, Heath S, Baurecht H, Novak N, Rodriguez E, Illiq T, Lee-Kirsch MA, Ciechanowicz A, Kurek M, Piskackova T, Macek M, Lee YA, Ruether A: A common variant on chromosome 11q13 is associated with atopic dermatitis. Nat Genet 2009, 41:596-601.

56. Lim ET, Raychaudhuri S, Sanders SJ, Stevens C, Sabo A, Macarthur DG, Neale BM, Kirby A, Ruderfer DM, Fromer M, Lek M, Liu L, Flannick J, Ripke S, Nagaswamy U, Muzny D, Reid JG, Hawes A, Newsham I, Wu Y, Lewis L, Dinh H, Gross S, Wang LS, Lin CF, Valladares O, Gabriel SB, dePristo M, Altshuler DM, Purcell SM, et al: Rare complete knockouts in humans: population distribution and significant role in autism spectrum disorders. Neuron 2013, 77:235-242.

57. Yang J, Visscher PM, Wray NR: Sporadic cases are the norm for complex disease. Eur J Hum Genet 2010, 18:1039-1043.

58. Lee SH, DeCandia TR, Ripke S, Yang J, Sullivan PF, Goddard ME, Keller MC, Visscher PM, Wray NR: Estimating the proportion of variation in susceptibility to schizophrenia captured by common SNPs. Nat Genet 2012, 44:247-250.

59. Kumar P, Henikoff S, Ng PC: Predicting the effects of coding nonsynonymous variants on protein function using the SIFT algorithm. Nat Protoc 2009, 4:1073-1081.

60. Adzhubei IA, Schmidt S, Peshkin L, Ramensky VE, Gerasimova A, Bork P, Kondrashov AS, Sunyaev SR: A method and server for predicting damaging missense mutations. Nat Methods 2010, 7:248-249.

61. Siepel A, Pollard K, Haussler D: New methods for detecting lineagespecific selection. In Proceedings of the 10th International Conference on Research in Computational Molecular Biology (RECOMB 2006). Berlin, heidelberg: Springer-Verlag; 2006:190-205.

62. da Huang W, Sherman BT, Lempicki RA: Systematic and integrative analysis of large gene lists using DAVID bioinformatics resources. Nat Protoc 2009, 4:44-57.

63. Ferreira MA, O'Donovan MC, Meng YA, Jones IR, Ruderfer DM, Jones $L$, Fan J, Kirov G, Perlis RH, Green EK, Smoller JW, Grozeva D, Stone J, Nikolov I, Chambert K, Hamshere ML, Nimgaonkar VL, Moskvina V, Thase ME, Caesar S, Sachs GS, Franklin J, Gordon-Smith K, Ardlie KG, Gabriel SB, Fraser C, Blumenstiel B, Defelice M, Breen G, Gill M, et al: Collaborative genomewide association analysis supports a role for ANK3 and CACNA1C in bipolar disorder. Nat Genet 2008, 40:1056-1058.

64. Schulze TG, Detera-Wadleigh SD, Akula N, Gupta A, Kassem L, Steele J, Pearl J, Strohmaier J, Breuer R, Schwarz M, Propping P, Nothen NM, Cichon S, Schumacher J, NIMH Genetics Initiative Bipolar Disorder Consortium, Rietschel M, McMahon FJ: Two variants in Ankyrin 3 (ANK3) are independent genetic risk factors for bipolar disorder. Mol Psychiatry 2009, 14:487-491.

65. Bi C, Wu J, Jiang T, Liu Q, Cai W, Yu P, Cai T, Zhao M, Jiang YH, Sun ZS: Mutations of ANK3 identified by exome sequencing are associated with Autism susceptibility. Hum Mutat 2012, 33:1635-1638. 
66. ENCODE Project Consortium, Dunham I, Kundaje A, Aldred SF, Collins PJ, Davis CA, Doyle F, Epstein CB, Frietze S, Harrow J, Kaul R, Khatun J, Lajoie BR, Landt SG, Lee BK, Pauli F, Rosenbloom KR, Sabo P, Safi A, Sanyal A, Shoresh N, Simon JM, Song L, Trinklein ND, Altschuler RC, Birney E, Brown JB, Cheng C, Djebali S, Dong $X$, et al: An integrated encyclopedia of DNA elements in the human genome. Nature 2012, 489:57-74

67. Bernstein BE, Stamatoyannopoulos JA, Costello JF, Ren B, Milosavljevic A, Meissner A, Kellis M, Marra MA, Beaudet AL, Ecker JR, Farnham PJ, Hirst M, Lander ES, Mikkelsen TS, Thomson JA: The NIH roadmap epigenomics mapping consortium. Nat Biotechnol 2010, 28:1045-1048.

68. Ward LD, Kellis M: Interpreting noncoding genetic variation in complex traits and human disease. Nat Biotechnol 2012, 30:1095-1106.

69. Barkovich RJ, Shtanko A, Shepherd JA, Lee PT, Myles DC, Tzagoloff A, Clarke CF: Characterization of the $\mathrm{COQ} 5$ gene from Saccharomyces cerevisiae. Evidence for a C-methyltransferase in ubiquinone biosynthesis. J Biol Chem 1997, 272:9182-9188.

70. Fukuhara N, Ebert J, Unterholzner L, Lindner D, Izaurralde E, Conti E: SMG7 is a 14-3-3-like adaptor in the nonsense-mediated mRNA decay pathway. Mol Cell 2005, 17:537-547.

71. Xu B, Roos JL, Dexheimer P, Boone B, Plummer B, Levy S, Gogos JA, Karayiorgou M: Exome sequencing supports a de novo mutational paradigm for schizophrenia. Nat Genet 2011, 43:864-868.

72. Girard SL, Gauthier J, Noreau A, Xiong L, Zhou S, Jouan L, Dionne-Laporte A, Spiegelman D, Henrion E, Diallo O: Increased exonic de novo mutation rate in individuals with schizophrenia. Nat Genet 2011, 43:860-863.

73. Rosenfeld JA, Mason CE, Smith TM: Limitations of the human reference genome for personalized genomics. PLOS One 2012, 7:e40294.

doi:10.1186/2040-2392-4-8

Cite this article as: Shi et al: Whole-genome sequencing in an autism multiplex family. Molecular Autism 2013 4:8.

\section{Submit your next manuscript to BioMed Central and take full advantage of:}

- Convenient online submission

- Thorough peer review

- No space constraints or color figure charges

- Immediate publication on acceptance

- Inclusion in PubMed, CAS, Scopus and Google Scholar

- Research which is freely available for redistribution

Submit your manuscript at www.biomedcentral.com/submit

C Biomed Central 